\title{
VITORIANOS, MODERNOS E SALVAGEPUNKS: REVERBERAÇÕES E ASSOMBROLOGIAS DO SÉCULO XIX
}

\author{
VICTORIANS, MODERNS, AND SALVAGEPUNKS: \\ $19^{\text {TH }}$ CENTURY REVERBERATIONS AND HAUNTOLOGIES
}

Sonia Torres ${ }^{1} 2$

Para Elisa Lima Abrantes, que um dia quis saber.

\begin{abstract}
RESUMO: A cultura contemporânea (tanto a high culture quanto a low culture) está cada vez mais enamorada do século XIX. Alguns exemplos que ilustram esta hipótese: os filmes dirigidos por Francis Ford Coppola, Jane Campion e Ang Lee; os romances de A. S. Byatt e William Gibson; as revisitas a Oscar Wilde e Lewis Carroll, fotografia nostálgica, produtos de computação gráfica, o cyberpunk e o steampunk. No texto desenvolvido aqui, discuto as reverberações da era vitoriana na contemporaneidade, argumentando que, a contrapelo da margem a que Pound relega o passado vitoriano, no início do século $X X$, o espectro persistente dos vitorianos ronda todas as formas de modernidade. Tais considerações dialogam com meus projetos de pesquisa de anos recentes ${ }^{3}$, sobre ficções especulativas contemporâneas, na medida em que gêneros como o steampunk e o salvagepunk têm como topos histórico predileto a era vitoriana. Busco argumentar que sua estética junk, mais do que recriar ou reapresentar tecnologias da era vitoriana, serve para avaliar os espectros de modernidades passadas que nos rondam.
\end{abstract}

$\boldsymbol{P A L A V R A S - C H A V E}$ : era vitoriana; século longo; século breve; modernidades.

ABSTRACT: Contemporary (high and low) culture is increasingly enamoured of the $19^{\text {th }}$ century. A few examples that support this argument are the films directed by Coppola, Jane Campion and Ang Lee; the novels written by A.S. Byatt and William Gibson; the revisits to Wilde and Carroll, nostalgic photography, graphic computing products, cyberpunk, and steampunk. In the text developed here, I discuss Victorian reverberations in contemporary culture, arguing that, against the grain of Pound's contention that "For most of us, the odour of defunct Victoriana is so unpleasant... that we are content to leave the past where we find it" (qtd in GARDINER, 2004, p. 168), the persistent ghost of Victoriana continues to haunt all forms of modernity. These considerations dialogue with my research interests of recent years, where I have privileged contemporary speculative fictions, in that for genre fictionspecifically steampunk and salvagepunk - the Victorian era is a favorite historical topos. I argue that their junk aesthetics, more than simply recreating or re-presenting technologies of

1 Doutora em Ciência da Literatura e Literatura Comparada pela UFRJ e professora titular aposentada no Instituto de Letras da Universidade Federal Fluminense (UFF). Bolsista Produtividade CNPq.

2 Este texto originou-se da palestra de encerramento, proferida por ocasião do III Colóquio Diálogos em Literaturas de Língua Inglesa, na Universidade Federal Rural do Rio de Janeiro, em 2013.

3 Ficções do pós-humano: revoluções (2010-2013); Pós-humanismo integrado vs. apocalíptico, ou o neoliberal vs. o pós-'colonial' (2014-2017); Ficção Especulativa na Era dos (pós)Humanos: o Antropoceno e a antropocena (2017-2020), todos com bolsa de produtividade em pesquisa do CNPq. 
a bygone era, serve to reassess the ghosts (in the machine) of past modernities that still haunt us.

KEYWORDS: Victorian era; long nineteenth-century; short twentieth-century; modernities.

Gostaria de introduzir minhas considerações lembrando-me das aulas no doutorado em literatura comparada, onde costumo insistir, entre jocosa e séria, que pertencemos, todos os presentes, independente de nossas variadas idades, ao século XIX. O que escrevo a seguir é, em grande medida, uma explicação para minha afirmação talvez um tanto bombástica. Mas é, também, uma resposta à provocação intelecto-afetuosa, por parte de alunos e ex-alunos, ao longo dos anos. Assim, eis que me vejo na posição de buscar respostas para uma pergunta pela qual sou a única responsável. Essa busca é tanto mais agradável e produtiva, na medida em que dialoga com meus próprios projetos de pesquisa.

Bem, ao preparar meu Plano de Trabalho, por assim dizer, tive de optar por um recorte e uma Metodologia (a Apresentação e Justificativa, e os Objetivos, já foram aqui brevemente expostos). Decidi ater-me ao âmbito do mundo anglófono, o que já é uma tarefa e tanto. ${ }^{4} \mathrm{Ah}$, sim, não poderia faltar a Hipótese com a qual estarei trabalhando: a cultura contemporânea (tanto a high culture quanto a low culture) está cada vez mais enamorada do século XIX. Alguns exemplos que ilustram esta hipótese: os filmes dirigidos por Francis Ford Coppola, Jane Campion e Ang Lee, com ótima recepção por parte da crítica e do público; os romances best-seller de A. S. Byatt e William Gibson; as revisitas a Oscar Wilde e Lewis Carroll, fotografia nostálgica, produtos de computação gráfica e o cyberpunk. Como metodologia, em um primeiro momento, optei por adotar os conceitos de "século longo" e "século breve", definidos por Hobsbawm. Em sua trilogia ${ }^{5}$ o historiador inglês analisa o século XIX como o período entre a Revolução Francesa e a Primeira Guerra Mundial; e em sua obra A Era dos Extremos: O Breve século XX, ele enfoca o período compreendido entre a Primeira Guerra e a queda da União Soviética. Como desdobramento, incluirei referências pontuais ao conceito de Long Victorian Era.

Então, a título de Introdução, se eu fosse apenas dar uma resposta ágil, teria dito que somos todos do longo século XIX porque todos nascemos no século breve, justaposto (se formos empregar a periodização proposta por Hobsbawm), por quase duas décadas, ao século longo; e porque ainda trazemos conosco noções do humanismo desenvolvidas pelos

4 Sem ignorar a enorme influência da Inglaterra do século XIX, sobretudo durante a longa era vitoriana, sobre o Brasil da belle époque. Mas aí já seria outro recorte, de cunho comparativo, que não caberia no espaço de que disponho aqui.

5 The Age of Revolution: Europe 1789-1848; The Age of Capital: 1848-1875; The Age of Empire: 1875-1914. 
pensadores da época e um vocabulário romântico; porque herdamos a fé na ciência, no progresso e no excepcionalismo subjacente a essas noções. É virtualmente impossível mapear todos os eventos do convulsivo século XIX que ainda nos impactam - seria apenas parte do relato (e aqui tomo emprestadas as palavras do poeta Walt Whitman) "da confusão, do calor, da fumaça e agitação daqueles tempos. A guerra em si, com o espírito da sociedade que a precede, pode ser melhor descrita pela palavra convulsão" (WHITMAN, 1892, p. 775, trad. livre $)^{6}$, que culminaria na produção em massa e na linha de montagem das fábricas, nas mudanças no espaço urbano e na emergência da metrópole. Enfim, grande parte do que entendemos por modernidade.

Contudo, vale lembrar que muitos escritores do início do século XX viam o século anterior com uma enorme distância, o oposto da modernidade, por assim dizer: "nos primeiros anos [do século XX], nenhum artista modernista ou liberal que se respeitasse desejaria pensar em si mesmo como filho da repressão, do realismo, do materialismo e do capitalismo laissez-faire" (BULLEN, 1997, p. 1-2). A fim de marcar suas diferenças como modernistas, autores como Virginia Woolf, T. S. Eliot e Wyndham Lewis negavam qualquer influência dos autores vitorianos. Em 1918 Ezra Pound (apud GARDINER, 2004, p. 168) chegou a cunhar o termo Victoriana, para se referir ao passado vitoriano de maneira pejorativa: "Para a maioria de nós, o odor da vitoriana defunta é tão desagradável...que ficamos contentes de deixar o passado onde ele se encontra". Ironicamente, para Hobsbawm, os modernistas ainda pertenciam ao longo século XIX.

Se, por um lado, constatamos que a era vitoriana foi usada como contraponto, para consolidar a identidade moderna - tipificada nas palavras de Pound -, por outro, há vários historiadores e críticos culturais que detectam traços culturais no século XIX que estabelecem continuidades entre aquele momento e o presente. ${ }^{7}$ Basta pensarmos no espaço urbano, outrora do flanêur, cujos boulevards e edifícios são agora um palimpsesto. Contudo, as reinscrições nunca efetuam o apagamento total do passado, produzindo um "choque de reconhecimento" no presente. Talvez o choque seja sentido em forma de estranhamento, no

6 Whitman, "Convulsiveness", seção 98 de Specimen Days. "As I have look'd over the proof-sheets of the preceding pages, I have once or twice fear'd that my diary would prove, at best, but a batch of convulsively written reminiscences. Well, be it so. They are but parts of the actual distraction, heat, smoke and excitement of those times. The war itself, with the temper of society preceding it, can indeed be best described by that very word convulsiveness". Grifo do autor.

7 Embora meu recorte aqui seja o mundo anglófono, a tentação é muito grande, e não posso deixar de mencionar o conhecido estudo de Roberto Schwarz sobre a obra de Machado de Assis e a política de troca de favores na modernidade brasileira. Cf. Schwarz, Roberto. "As ideias fora de lugar", in Ao vencedor, As Batatas: forma literária e processo social nos inícios do romance brasileiro. SP: Editora 34, 2000. 
sentido do Unheimlich de que fala Freud ([1919]-2010): aquilo que nos inquieta porque é, ao um mesmo tempo, familiar e estranho.

Essa imagem de palimpsesto ativa minha memória para 1985, na PUC-RJ, onde eu era aluna. Era o auge das discussões sobre o que é o pós-moderno, se o pós-moderno existe etc. Neste mesmo ano, Jean-François Lyotard foi curador de uma exposição intitulada Les Immatériaux, no Centro Georges Pompidou, concebida como uma "dramaturgia da informação para a condição pós-moderna" (RAJCHMAN, 2009, p. 1). Lyotard levava os visitantes a passar por um labirinto de objetos os mais variados - de robôs industriais de última geração, PCs, hologramas, instalações interativas, cinema 3D, pinturas, fotografias e esculturas de diferentes épocas, até obras não-ocidentais e "antigas" misturadas à arte conceitual de Dan Graham -, usando fones de ouvido com gravações de "grandes" escritores modernistas lendo trechos de suas obras. A exposição sugeria, dessa forma, que o pósmodernismo emergiu sob a égide do modernismo, e se alimenta, em grande medida, da trilha sonora do mesmo.

A fusão de proximidade e distância, reconhecimento e desfamiliarização, manifesta-se nas imagens múltiplas, e frequentemente contraditórias, que o passado evoca na memória e no imaginário do presente. Se, conforme argumenta Gilmour (1993), ainda vivemos sob a imensa sombra projetada pelo século XIX, essa assombrologia - para empregar uma linguagem de espectralidade, inspirada em Derrida $^{8}$ - dos espectros que rondam a modernidade tardia está presente no texto literário, que funciona frequentemente como mediador dessa inquietante repetição ou reverberação do passado no presente. Não se trata apenas da interpretação de uma visão do passado, mas da revisão e reinterpretação de como esse passado se liga ao presente.

Por associação, sou levada a outra exposição, desta vez no Science Museum de Londres, em 1991. O museu mandou construir uma máquina, The Difference Engine, conforme projetada por Charles Babbage, no século XIX. Como observa Francis Spufford (1997, p. 268), ao recriar a máquina, foi dada a ela, retrospectivamente, um lugar na história da ciência do computador. O mais interessante é que foi, em grande medida, por falta de uma linguagem através da qual pudesse conceituar ou mesmo expressar suas ideias, que Babbage não conseguiu terminar de construir a máquina. Mas quando o museu a construiu, as soluções

8 Refiro-me à hauntologie invocada por Derrida - conceito que sugere um jogo com ontologia. No trabalho do filósofo, a desconstrução do século XX não é incompatível com os fundamentos de MarX, do longo século XIX, e o espectro do filósofo marxista ronda o "século breve". Ver DERRIDA, Jacques. Espectros de Marx. Trad. Anamaria Skinner. Rio de Janeiro: Relume-Dumará, 1994. 
para os problemas foram encontradas, porque já haviam sido desenvolvidas, nos cem anos que se passaram, tecnologias de suporte. Ou seja, caso Babbage a construísse hoje, sua máquina funcionaria perfeitamente. Nesse episódio ficam evidentes duas coisas: o legado do século XIX, e como é problemático se proporem tanto rupturas quanto continuidades entre as épocas.

Aqui eu faço um breve atalho, para justificar a eventual oscilação entre o emprego da expressão "século XIX", e o termo normalmente mais restrito, "vitoriano". Simon Joyce $(2002$, p. 7) escreveu que o termo "vitoriano" passou a ser empregado imediatamente após a morte da rainha Vitória, em 1901, cunhado por jornalistas para designar o período de seu reino. Taylor $(2004$, p. 3) argumenta, porém, que o termo já era usado em 1851 ou, pelo menos, já durante os anos do Jubileu, entre 1887-1897, em que era empregado para descrever uma época histórica, com sua própria poesia, literatura, música e heróis militares. O fato é que o termo se consagra no final do século XIX, e muitos escritores classificados como vitorianos não viveram e escreveram, estritamente falando, no período descrito por Taylor. Sendo assim, vários críticos literários empregam o termo "vitoriano" para descrever uma era que abrange mais de 60 anos. Na introdução a Rereading Victorian Fiction, Alice Jenkins e Juliet John (2002, p. 2) admitem a dificuldade de conceituar "vitoriana", observando que o termo pode ser entendido tanto cronologicamente quanto não-cronologicamente, e assinalando que a diversidade de leituras que disto resulta é um meio construtivo de evitar interpretações que limitam o período vitoriano a mitos totalizantes. Mesmo empreendendo um breve levantamento, constata-se que a ampliação do conceito parece ser cada vez mais corrente. Concluímos tratar-se de um termo que vem acumulando significados múltiplos, muitas vezes "colonizando" várias décadas antes e depois do reino da Vitória. Seja como for, impor cortes epistemológicos na história é sempre um empreendimento suspeito, e na história literária é, no mínimo, capcioso.

Desta forma, tomemos vitoriano mais como um conceito ou ideia do que o período específico (1837-1901) da história britânica coincidindo com o reinado da Vitória. Apesar de que seu reino foi o mais longo da história da Inglaterra - até 2015, quando foi suplantado pelo da atual rainha Elizabeth. Em seu Prefácio a The Victorians, A.N. Wilson (2002, p. 1) argumenta que “...os vitorianos continuam conosco porque o mundo que criaram continua aí, apesar das mudanças" -

Theirs was the period of the most radical transformation ever seen by the world. Before them major industrialization was confined to a few towns in Britain. After them, the whole world was covered with railways and factories; and the 
unstoppable rise and spread of technology would continue into the age of Silicon Valley. (WILSON, 2002, p. 1)

O difference engine não desmente suas palavras...

$\mathrm{Na}$ Introdução a Victorian Afterlife, John Kucich e Dianne F. Sadoff (2000) empregam o termo "vitoriano" de forma intercambiável com "século XIX", estendendo e adaptando o "long" de long Victorian era para incluir as adaptações cinematográficas de Bram Stoker, E. M. Forster e Jane Austen por diretores como Francis Ford Coppola, Jane Campion e Ang Lee', que, nas palavras desses autores, "projetam um feeling vitoriano tanto nos textos da era Regency como nos do alto-modernismo". (KUCICH; SADOFF, 2000, p. x, xi). É o chamado neo-Victorian, ou "neo Vic". A pergunta que guia o trabalho dos autores e editores está implícita na Introdução ao volume de ensaios: "Por que o pós-modernismo se volta para o século XIX como seara crucial de uma ruptura histórica?” (KUCICH; SADOFF, 2000 , p. xvii) - sugerindo uma afinidade entre aquele século e o tempo presente. ${ }^{10}$

Cabe, portanto, refletir sobre a obsessão contemporânea com a era entendida, de forma bastante flexível, como vitoriana. Haja vista a vasta bibliografia disponível, para quem quiser se aprofundar no assunto: Nostalgic Postmodernism: The Victorian Tradition and the Contemporary British Novel, de Christian Gutleben (2001), Functions of Victorian Culture at the Present Time, de Christine Krueger (2002), The Victorians Since 1901: Histories, Representations and Revisions, de Miles Taylor e Michael Wolff (2004), só para ficarmos com alguns livros. Isto para não falar nas publicações em que consta o termo "neovitoriano": existe até um periódico, The Journal of Neo-Victorian Studies, dedicado ao assunto. No ensaio inaugural do número de estreia, a editora, Marie-Louise Kohlke (2008, p. 1), abre com uma defesa dos estudos neovitorianos como uma área independente, argumentando que "[a] produção de artefatos, ficções e fantasias neovitorianas já se tornou prolífera demais para ficar relegada ao canto da sala-de-estar dos estudos vitorianos, qual espectro..." 11

$\mathrm{Na}$ Introdução a Functions of Victorian Culture at the Present Time, Christine Krueger (2002) emprega o termo pós-vitoriano, numa alusão, a um mesmo tempo, ao conhecido ensaio de Matthew Arnold "The Function of Criticism at the Present Time" (não acidentalmente, de 1864) e ao pós-modernismo. Seu objetivo é demonstrar que as releituras do presente nada mais são do que uma complexa relação com a ética, política e arte dos

9 Cf. Bram Stoker's Dracula, dir. Francis Ford Coppola (1992); The Portrait of a Lady, dir. Jane Campion; e Sense and Sensibility, dir. Ang Lee (1995).

10 Também fica implícita uma certa leitura da era Regency da Austen como proto-vitoriana.

11 Tradução livre de "...the production of neo-Victorian artefacts, fictions, and fantasies has become too prolific to be contained as a ghost in the corner of the Victorian Studies parlour..." 
antepassados do século XIX (cf. KRUEGER, 2002, p. xi). Simon Joyce (2002, p. 13) argumenta, no mesmo volume, que enquanto os modernistas "relegaram os vitorianos ao passado", os pós-modernos "enxergam a força residual do vitoriano" como um conceito que "tem sido transcendido, negado, parodiado e ressuscitado desde seu suposto desaparecimento" (JOYCE, 2002, p. 15).

Um crítico que constrói a relação contemporânea com a era vitoriana em termos de continuidade é Robin Gilmour, que vê o movimento arquitetônico Vernacular Revival contemporâneo, inspirado no Arts and Crafts Movement (1880-1920) ${ }^{12}$, essencialmente antiindustrial, como um despertar para as virtudes da vida regional, que pode ser identificado como uma reação à mudança acelerada trazida pela crescente industrialização, urbanização e produção em massa. ${ }^{13}$ Tais mudanças interconectam a experiência cotidiana dos cidadãos do século XIX ao impacto produzido pela cultura tecnocientífica, nos séculos XX e XXI. Assim como, na cultura contemporânea, a introdução da informação virtual e o desenvolvimento de novas tecnologias relacionadas à web continua a transformar os sistemas de comunicação e informação a passo acelerado, os vitorianos testemunharam e viveram o surgimento de vastas transformações em sua estrutura de comunicação que produziram uma saturação da informação comparável à dos dias de hoje, com a construção de um sistema ferroviário extenso, a redução no tempo e nos custos postais com o estabelecimento do "penny post" e a proliferação de jornais (cf. GILMOUR, 1993, p. 230).

Dentro de uma abordagem similar, só que ainda mais radical (e divertida, diga-se de passagem), vale mencionar o trabalho de Matthew Sweet, Inventing the Victorians, onde ele propõe expor a Victorianness do mundo em que vivemos, apontando que herdamos dos vitorianos muitos dos recursos culturais que consideramos exclusivamente nossos, como o parque temático, o shopping, o jornalismo investigativo, os lobistas, a educação gratuita e a pornografia (SWEET, 2001, p. xi-xii). Sua pesquisa "libera" os vitorianos das histórias "absolutamente falsas" que têm sido apresentadas como verdadeiras. Segundo ele, tais histórias foram perpetuadas porque preferimos pensar nos vitorianos como "figuras contra as quais nos rebelamos" e sugerir o contrário seria minar um dos "mitos fundadores da modernidade" (SWEET, 2001, p. 230-231).

$12 \mathrm{O}$ Arts and Crafts Movement pregava a reforma social e econômica; na arquitetura predominava a simplicidade nas formas, e materiais inspirados na arte popular, remontando ao medievo ou ao período romântico.

13 Não tão afastado dos movimentos por sustentabilidade e da ecocrítica dos dias atuais. 
No Prefácio à sua conhecida obra Culture and Society, Raymond Williams ([1958]1983, p. xv) enumera palavras que foram cunhadas ou reinventadas durante a era vitoriana, e que nos foram legadas: ideologia, racionalismo, humanitário, igualitário, liberalismo, massas, entre muitas outras. No século XXI, ainda somos moldados, em grande medida, pelos conceitos e valores que tais palavras conotam. Vemos, então, que, a contrapelo da margem a que Pound relega o passado vitoriano, no início do século $\mathrm{XX}$, já a partir do primeiro quarto do mesmo século começou a surgir um interesse crescente no século XIX, em especial na era vitoriana. Essa fascinação invadiu o cinema, a TV, a moda, a propaganda e as pesquisas acadêmicas. $\mathrm{Na}$ contemporaneidade, um número crescente de ficcionistas escrevendo em língua inglesa envereda pelo século XIX, empregando as mais variadas estratégias narrativas. Cito aqui os exemplos de A. S. Byatt (1990), com Possession e Graham Swift (1992), com Ever After, que convocam dois momentos históricos - o contemporâneo e o século XIX - em histórias paralelas que dramatizam o processo de reconstrução de um tempo passado. Nestas obras, como sugere Mark Llewellyn (2008, p. 170), “a importância do palimpsesto está, não na escritura de novos textos sobre antigos textos, mas na existência simultânea de ambas as narrativas na mesma página, ocupando o mesmo espaço, e falando de maneiras estranhas, obscuras, uma com a outra".

Já em The Difference Engine, de William Gibson e Bruce Sperling (1988), Sixty Lights, de Gail Jones (2006) e Specimen Days, de Michael Cunningham (2005), a ontoepistemologia (a hauntologie) do século XIX se justapõe à da contemporaneidade, através de eventos históricos como o colonialismo, a democracia, o Triangle Fire de 1911 em Nova York, os acidentes nas fábricas, a experiência da metrópole em expansão, a descoberta da fotografia e a crise da fé na ciência e tecnologia. Há, ainda, autores que optam por reinventar personagens do século XIX, como Peter Carey (1998), que, em Jack Maggs, explora o personagem Magwitch de Great Expectations, de Charles Dickens através de seu “descendente"; e Emma Tennant (1994) que, em seu romance Tess, cria descendentes para Tess of the D'Urbervilles, de Thomas Hardy. Há ainda os ficcionistas que reescreveram romances vitorianos. É o caso de Wide Sargasso Sea, de Jean Rhys (1966), que explora a figura sombria ou à sombra de Bertha Mason, personagem de Jane Eyre (1847), de Charlotte Brontë; de Mary Reilly, de Valerie Martin (1990), que retrabalha The Strange Case of Dr Jekyll and Mr Hyde (1886) da perspectiva da criada; e Adèle, de Emma Tennant (2003), em que o foco narrativo é deslocado para a filha de Rochester, outra personagem de Jane Eyre.

Algumas dessas formas ficcionais vêm na esteira do pastiche e da paródia pósmodernos; outras vêm das releituras pós-coloniais de obras canônicas em língua inglesa ou da 
metaficção historiográfica de que fala Linda Hutcheon (1988). Essas últimas ficções demonstram consciência do quão complexo é se buscar o conhecimento histórico, e problematizam a representação do passado como "verdade" absoluta. Contudo, o intuito desta perambulação não é o de categorizar tais produções dentro das teorizações acadêmicas, e sim, ao buscar respostas, formular perguntas. Podem esses romances recriar o passado de maneira significativa? Sobretudo, no caso das obras que convocam eventos históricos, de que maneira elas levantam questões sobre nosso próprio momento histórico, através da ficção?

Isto me traz de volta ao difference engine, e ao romance cyberpunk homônimo de William Gibson e Bruce Sterling, de 1988. The Difference Engine é uma história alternativa, onde os autores imaginam que o proto computador de Charles Babbage fora, de fato, construído. Esse tipo de ficção histórica explora não o que ocorreu de fato, mas o que poderia ter sido, sugerindo que os eventos históricos são contingências, e não consequências, de determinada época. O romance serve para nos lembrar que as vastas mudanças tecnológicas do breve século XX, que reverberam no século XXI - e o impacto cultural delas resultantes -, são o resultado de processos que tanto impactaram quanto sofreram o impacto das tecnologias e manifestações culturais do século XIX.

Há, ainda, muitas outras obras cyberpunk que, ao representarem um futuro distópico, com suas paisagens urbanas labirínticas, remetem para o gótico urbano do século XIX: para a cidade invisível, escondida, e para as implicações frankensteinianas de se criar vida artificial. É o caso, por exemplo, de Neuromancer, de William Gibson (1984), e de Do Androids Dream of Electric Sheep?, de Philip K. Dick (1968), e sua consagrada e cult versão cinematográfica de Ridley Scott, Blade Runner (1984).

Ainda dentro desse gênero de ficções, que podemos situar entre a fantasia e a ficção científica, e que configuram e reconfiguram tanto o velho quanto o novo de forma distorcida - e já me encaminhando para o final destas breves reflexões - gostaria de me referir ao steampunk, que surge mais para o final da década de 1980. Enquanto o cyberpunk lida com as questões críticas da ficção científica tradicional, adaptando-as às identidades fluidas do pósmoderno ou pós-humano, o steampunk, com sua estética retrô-futurista, tem sido criticado por reificar e, por vezes, romantizar as formas industriais da era vitoriana, através da apresentação de mundos alternativos, em que os estilos e tecnologias do século XIX são reconfigurados e distorcidos, para produzir ambientes a um mesmo tempo futurológicos e nostálgicos, trazendo o século longo de volta de maneira romantizada, fetichizando os artefatos, sobretudo os industriais, da época. 
Queria argumentar que a obra do inglês China Miéville contraria as críticas de que o steampunk seria um gênero reacionário. Os três romances que compõem a trilogia bas-lag ${ }^{14}$ de Miéville, Perdido Street Station (2000), The Scar (2002) e Iron Council (2004), são ambientados num mundo ficcional típico do steampunk, que incorpora elementos de diferentes gêneros. O universo de fantasia é povoado por humanos e outras espécies inteligentes; e a tecnologia movida a carvão e vapor da era vitoriana tem empregos futurológicos. Contudo, ao contrário de fetichizar o passado vitoriano através de uma estética nostálgica ou de mero pastiche, o texto de Miéville tem uma estética junk - uma espécie de refugo de modernidades de outrora - que convoca para dentro do texto os paradoxos da continuidade e da ruptura históricas. Ao entretecer tecnologias, identidades e o (bio)poder do estado do passado com os do presente, Miéville sugere que nem o passado histórico nem a fantasia presente escapam do controle social e de hierarquias opressivas.

Evan Calder Williams (2011) cunhou o termo salvagepunk, para referir-se à estética junk de modernidades perdidas ou descartadas, de uma visão pós-apocalíptica de um mundo quebrado e morto. Para este autor, o steampunk é "a aia fraca do capitalismo da era Obama", e a promessa subjacente ao gênero seria a de "manter a tecnologia, manter o consumo, porém de maneira 'consciente', responsável, 'sustentável' " - enfim, "lembr[ar] o que a era [vitoriana] nunca foi (dream world), no tempo em que a vida era mais simples e o trabalho fazia sentido" (WILLIAMS, 2011, p. 19).

O salvagepunk, ao contrário, trata de salvar, retrabalhar ${ }^{15}$, re-unir, reutilizar esses fragmentos do passado, para buscar compreender nossa condição no presente $(\text { dream work })^{16}$. Nesse sentido, o século XIX, e a era vitoriana, em especial, servem como o tempo/espaço do qual surgiram muitos dos fenômenos culturais e as tensões que são parte, ainda, de nossa experiência na modernidade tardia: as relações entre o humano e o ambiente; entre sociedade e tecnologia; negociações de gênero, etnia e raça e economia capitalista de um passado que ainda não passou:

14 Universo steampunk criado por Miéville, bas-lag possui inúmeros continentes, ilhas e cidades, e seus romances costumam abrir com um mapa, para situar o leitor.

15 Curiosamente, há personagens no obra de Miéville chamados Remades - apesar de, em geral, serem refeitos pelo Estado, como punição por crimes cometidos.

16 Dream work é uma linha psicanalítica de interpretação de sonhos que incentiva se explorarem as imagens e emoções que determinado sonho apresenta e evoca, sem buscar uma interpretação definitiva, de maneira que o sonho permanece "inacabado", em processo. 
...we are not talking about dream residues of a world, the nostalgic fantasies and fashionings of what once was. Rather, these are residues of a dream world that form a historical border to the next era, not as blueprints or utopian plans, but as leftovers. Rather, they are the unwelcome remainder of what won't go away. For what matters is neither manifest nor latent dream content. It's always the dream work, the underground currents that actually expose the loops of repression and the labor of making something out of these remnants. (CALDER, 2011, p. 16)

Como críticos de literatura e cultura, sejamos, portanto, salvagepunks e dream workers. Busquemos nos sonhos e projetos descartados do passado novos significados e utopias que nos levem, sempre, a novas reflexões sobre o presente. E, possivelmente, confirmaremos que somos todos do século XIX e que - tomando emprestadas as palavras de Bruno Latour (1993), talvez nunca tenhamos sido modernos.

\section{REFERÊNCIAS}

ARNALD, Matthew. Four essays on life and letters: the function of criticism at the present time (1864); Sweetness and light (1867); The study of poetry (1880); Literature and science (1882). New York: Appleton-Century-Crofts/Mass Market Paperback, 1947.

BULLEN, J.B., ed. Writing and Victorianism. London: Longman, 1997.

BYATT, A. S. Possession: a romance. New York: Vintage, 1990.

CAREY, Peter. Jack Maggs. New York: Knopf, 1998.

CUNNINGHAM, Michael. Specimen days. New York: Farrar, Straus, Giroux, 2005.

DICK, Philip K. Do androids dream of electric sheep? New York: Doubleday, 1968.

FREUD, Sigmund (1919). O inquietante, in Obras completas de Sigmund Freud, v. 14. Trad. Paulo Cesar Soura. São Paulo: Companhia das Letras, 2010.

GARDINER, John. "Theme-park Victoriana", in The Victorians since 1901: histories, representations and revisions, ed. M. Taylor e M. Wolff, p. 167-180. Manchester: Manchester UP, 2004.

GIBSON, William; SPERLING, Bruce. The difference engine. New York: Bantam Books, 1991.

GIBSON, William. Neuromancer. New York: Mass Market, 1984.

GILMOUR, Robin. The Victorian period: the intellectual and cultural context of English literature, 1830-1890. Longman Literature in English Series. London: Longman, 1993.

GUTLEBEN, Christian. Nostalgic postmodernism: The Victorian tradition and the contemporary British novel. Postmodern studies, Book 31, Amsterdam: Rodopi, 2001.

HOBSBAWM, Eric. Era dos extremos: o breve século XX -1914-1991. Trad. Marcos Santarrita. 2. ed. São Paulo: Companhia das Letras, 1995.

HUTCHEON, Linda. A poetics of postmodernism: history, theory, fiction. New York: 1988.

JENKINS, Alice; JOHN, Juliet. Rereading Victorian fiction. Basingstoke: PalgraveMacmillan, 2002.

JONES, Gail. Sixty lights. New York: Vintage, 2006.

JOYCE, Simon. "The Victorians in the rearview mirror", in Functions of Victorian culture at the present time, ed. C. L. Krueger, p. 3-17. Athens: Athens UP, 2002.

KOHLKE, Marie-Louise. Introduction: speculations in and on the neo-Victorian encounter. Neo-Victorian studies, v. 1, n. 1, p. 1-18, 2008.

KRUEGER, Christine L. Functions of Victorian culture at the present time. Athens: Ohio UP, 2002. 
KUCICH, John; SADOFF, Dianne F. Victorian afterlife: postmodern culture rewrites the nineteenth-century. Minneapolis: U of Minnesota P., 2000.

LATOUR, Bruno. We have never been modern. Tradução do francês de Catherine Porter. Massachussetts: Harvard U P, 1993.

LEWELLYN, Mark. "What is neo-Victorian studies?" Neo-Victorian studies, v. 1, n. 1, p. 164-185 (Autumn), 2008.

MARTIN, Valerie. Mary Reilly. New York: Doubleday, 1990.

MIÉVILLE, China. Perdido street station. London: Macmillan, 2000.

. The scar. London: Macmillan, 2002.

. Iron council. London: Del Rey, 2004.

RAJCHMAN, John. "Les immatériaux: or how to construct the history of exhibitions". Tate's

Online Research Journal, v. 12, p. 1-7, 2009. Disp. http://www.tate.org.uk/download/file/fid/7271 Último acesso: 18/082018.

RHYS, Jean. Wide sargasso sea. New York: Norton, 1966.

SPUFFORD, Francis.; UGLOW, Jenny. Cultural babbage: technology, time and invention. London: Faber \& Faber, 1997.

SWEET, Matthew. Inventing the Victorians. London: Faber and Faber, 2001.

SWIFT, Graham. Ever after. New York: Knopf, 1992.

TAYLOR, Miles. Introduction, in The Victorians since 1901: histories, representations and revisions, ed. M. Taylor e M. Wolff, p. 1-16. Manchester: Manchester UP, 2004.

TENNANT, Emma. Tess. New York: Flamingo [Harper-Collins], 1994.

. Adele: Jane Eyre's hidden story. Waterville: Thorndike Press, 2003.

WHITMAN, Walt. "Convulsiveness". In Specimen day: from complete poetry and collected prose - 1819-1892, p 775. Electronic Text Center, University of Virginia Library. Disp:https://web.archive.org/web/20081201222949/http://etext.lib.virginia.edu/toc/modeng/p ublic/WhiPro1.html Último acesso: 18/08/2018.

WILLIAMS, Evan Calder. Combined and uneven apocalypse. s.1.: Zero Books, 2011.

WILLIAMS, Raymond [1958]. Culture and society:1780-1950. 2.ed. New York: Columbia UP, 1983.

WILSON, A.N. The Victorians. New York: W.W. Norton, 2002.

Recebido em 19/08/2018. Aceito em 24/10/2018. 